\title{
Erratum to: Genome sizes in diploid and allopolyploid Arachis L. species (section Arachis)
}

\author{
Sergio Sebastián Samoluk • Laura Chalup • \\ Germán Robledo · José Guillermo Seijo
}

Received: 14 June 2014/Accepted: 27 October 2014/Published online: 17 January 2015

(C) Springer Science+Business Media Dordrecht 2015

\section{Erratum to: Genet Resour Crop Evol DOI 10.1007/s10722-014-0193-3}

We regret but noticed the following corrections went required;

Herewith please find a renewed Fig. 1 to replace the former published which contained an inadequately marked distribution border line.
Secondly, in the Materials and methods, Flow cytometry section, the name "Paspalum notatum Chirú byotype" should have read "Paspalum dilatatum Chirú Q4081".

Furthermore, the last article section "The constancy in the Cx values suggests that the hybridization and chromosome doubling events that occurred during the origin of the cultivated peanut did not

The online version of the original article can be found under doi:10.1007/s10722-014-0193-3.

S. S. Samoluk $(\bowtie) \cdot$ L. Chalup · G. Robledo · J. G. Seijo Instituto de Botánica del Nordeste (UNNE - Facultad de Ciencias Agrarias - CONICET), Casilla de Correo 209, 3400 Corrientes, Argentina

e-mail: samocarp@hotmail.com

L. Chalup

e-mail: lchalup@agr.unne.edu.ar

G. Robledo

e-mail: grobledo@agr.unne.edu.ar

J. G. Seijo

e-mail: seijo@agr.unne.edu.ar

G. Robledo · J. G. Seijo

Facultad de Ciencias Exactas y Naturales y Agrimensura (UNNE), Av. Libertad 5460, 3400 Corrientes, Argentina 


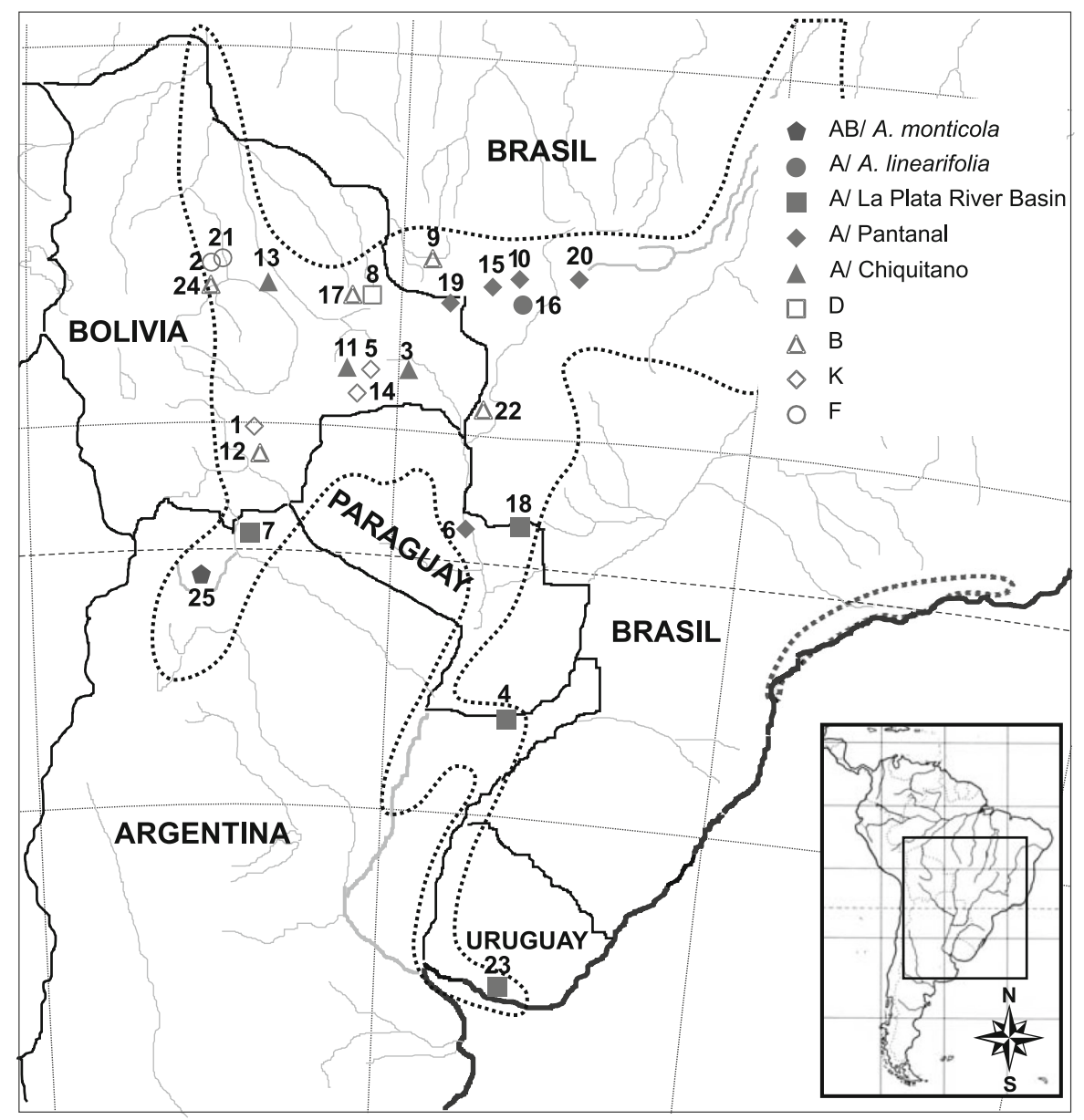

Fig. 1 Geographic distribution of the localities in which the accessions of the wild Arachis species analysed in this study were collected. For location details and species code see

induced significant changes in genome size." should read "The constancy in the $\mathrm{Cx}$ values suggests that the hybridization and chromosome doubling events
Table 1. The dash-dotted line denotes the distribution of the Arachis section. Each genome and karyotype group (of the A genome) is indicated with different symbol

that occurred during the origin of the cultivated peanut did not induce significant changes in genome size." 